\title{
Pengaruh Jenis Pupuk Kandang terhadap Pertumbuhan dan Hasil Dua Varietas Okra (Abelmoschus esculentus L. Moench)
}

\section{The Effect of Manure on Growth and Yield of Two Okra Varieties (Abelmoschus esculentus L. Moench)}

\author{
Sri Nanda Sofiana ${ }^{1}$ Jumini $^{1}$, Erida Nurahmi ${ }^{{ }^{*}}$ \\ ${ }^{1}$ Mahasiswa Jurusan Agroteknologi, Fakultas Pertanian, Universitas Syiah Kuala \\ ${ }^{2}$ Staf Pengajar Jurusan Studi Agroteknologi, Fakultas Pertanian, Universitas Syiah Kuala
}

\begin{abstract}
ABSTRAK
Abstrak. Penelitian ini bertujuan untuk mengetahui pengaruh jenis pupuk kandang terhadap pertumbuhan dan hasil dua varietas okra. Penelitian ini dilaksanakan di Kebun Percobaan dan Laboratorium Fisiologi Tumbuhan Jurusan Agroteknologi Fakultas Pertanian Universitas Syiah Kuala, Darussalam, Banda Aceh pada ketinggian 0,80 mdpl, memiliki jenis tanah Alluvial dan dilaksanakan pada bulan Juni sampai dengan September 2019. Penelitian ini menggunakan Rancangan Acak Kelompok pola faktorial 2x4 yang terdiri dari 2 faktor yaitu: varietas okra dan jenis pupuk kandang. Secara keseluruhan terdapat 8 kombinasi perlakuan. Masing-masing perlakuan diulang sebanyak 3 kali sehingga penelitian ini memiliki 24 satuan percobaan. Pada setiap satuan percobaan terdapat 3 tanaman sehingga terdapat 72 satuan percobaan. Hasil penelitian menunjukkan bahwa varietas berpengaruh nyata terhadap tinggi tanaman umur 15 dan 30 HST. Jenis pupuk kandang berpengaruh sangat nyata terhadap tinggi tanaman 60 HST dan berpengaruh nyata terhadap tinggi tanaman umur 45 HST. Terdapat interaksi yang nyata antara perlakuan 2 varietas dengan jenis pupuk kandang terhadap tinggi tanaman umur 60 HST. Kombinasi perlakuan yang lebih baik dijumpai pada okra hijau varietas Naila IPB dan pupuk kandang kambing.
\end{abstract}

Kata kunci. Okra, varietas, dan pupuk kandang

\section{ABSTRACT}

Abstract. This study aims to determine the effect of manure on the growth and yield of 2 okra varieties. This research was conducted at the Experimental Garden and Plant Physiology Laboratory of the Department of Agrotechnology, Faculty of Agriculture, Syiah Kuala University, Darussalam, Banda Aceh, at an altitude of 0.80 masl, having Aluvial soil types and carried out from June to September 2019. This research used a Randomized Group Design (Group Random Design) 2x4 with factorial pattern consists of 2 factors: okra variety and type of manure. In total, there are 8 treatment combinations. Each treatment was repeated 3 times so that this study had 24 experimental units. In each unit of experiment there are 3 plants so there are 72 units of experiment. The results of this study indicate that the varieties have a significant effect on plant height at age of 15 and 30 DAP. The type of manure has a very significant effect on plant height of $60 \mathrm{DAP}$ and significantly affects plant height at age of $45 \mathrm{DAP}$. There was a real interaction between the treatment of 2 varieties with types of manure on the height of the plant aged 60 DAP. The combination of better treatments was found in green okra varieties Naila IPB and goat manure.

Keywords. Okra, varieties, and manure

\section{PENDAHULUAN}

Okra (Abelmoschus esculentus L. Moench) sering disebut sebagai kacang bendi dan dikenal dengan nama "Lady's Finger" karena tanaman okra memiliki bentuk buah silindris dan berujung runcing mirip dengan jari-jari wanita. Tanaman okra termasuk kedalam famili Malvaceae (kapas-kapasan), karena buahnya berbentuk silindris dan berujung runcing seperti jari wanita. Okra termasuk famili Malvaceae (kapas-kapasan), yang banyak dibudidayakan di daerah tropis dan subtropis diseluruh dunia termasuk Indonesia (Wasito, 2018). Buah okra dapat dikonsumsi dengan berbagai cara seperti 
dimasak dan dimakan mentah (Kumar et al., 2013). Setiap bagian tubuh tanaman okra dapat dimanfaatkan sebagai obat-obatan, hampir semua bagian dari tubuh memiliki fungsi tersendiri dari biji, akar, daun, batang, bunga dan buah. Okra merupakan tanaman yang memiliki kandungan gizi yang tinggi dan juga berguna sebagai obat-obatan tradisional untuk menurunkan resiko penyakit kronis, penyakit jantung koroner, obesitas, gangguan gastrointestinal (GI), hiperkolesterolemia dan hipertensi (Watson dan Preedy, 2016). Okra perlu dilakukan beberapa penelitian yang bertujuan agar dapat menghasilkan produksi yang tinggi (kuantitas) dan kualitas yang sesuai dengan keinginan dari konsumen. Kualitas dari buah akra dapat dinilai dari penampakan (warna, bentuk, ukuran), kandungan bioaktif dan kandungan gizi yang ada di dalamnya (Hariyadi, 2009). Banyaknya manfaat okra menyebabkan meningkatnya permintaan okra. Namun produksi okra dibatasi oleh berbagai faktor lingkungan seperti air, tanah, pupuk, dan pemilihan varietas yang unggul. Faktor lingkungan tumbuh seperti kesuburan tanah sebagai media tanaman menjadi masalah tersendiri. Hal ini dikarenakan penurunan kesuburan tanah dan rendahnya bahan organik. Okra merupakan tanaman yang diperbanyak secara generatif melalui benih. Hal yang perlu diperhatikan apabila perbanyakan okra menggunakan benih adalah pemilihan varietas, karena pemilihan varietas juga mempengaruhi hasil dan kualitas dari okra. Varietas unggul adalah varietas yang dikolompokkan dari sifat yang paling menonjol yang memagang peran penting untuk kontribusinya dalam menikngkatkan produktivitas dan kualitas yang ada pada tanaman tersebut (Badan Litbang Pertanian Kementrian Pertanian Republik Indonesia, 2019). Menurut Barus et al (2018) setiap jenis pupuk memiliki unsur hara yang berbeda-beda yang berakibat pada produksi dan kualitas produk. Ibrahim et al. (2013) menjelaskan bahwa kadar total fenol, kandungan gula terlarut dan flavonoid pada tanaman Kacip Fatimah (Labisia pumila) dapat mengalami peningkatan dengan pemberian pupuk organik. Wibowo et al. (2015) telah meneliti tentang kombinasi pupuk kandang berguna untuk pertumbuhan yang ada pada daun okra. Menurut Muhammad (2015) dengan di berikannya pupuk kandang ayam, sapi dan kambing sebanyak 20 ton $\mathrm{ha}^{-1}$ adalah dosis yang paling cocok untuk pertumbuhan dan perkembangan tinggi tanaman, jumlah daun dan cabag pertanaman. Berdasarkan penelitian Manik et al. (2019) pemberian pupuk kandang sapi dengan dosis 15 ton ha ${ }^{-1}$ mampu meningkatkan produksi dan memperbaiki kualitas buah pada tanaman okra. Pemberian pupuk kandang kambing 20 ton ha ${ }^{-1}$ dapat memperbaiki sifat kimia tanah, meningkatkan nutrisi pada tanah dan dapat meningkatkan hasil jagung manis (Uwah dan Eyo, 2014). Menurut Maisa dan Yetti (2018) pemberian pupuk kandang ayam 17,5 ton ha $^{-1}$ berpengaruh nyata terhadap pertumbuhan tinggi tanaman, jumlah anakan, berat segar, dan berat per rumpun pada bawang daun. Penelitian ini bertujuan untuk mengetahui pengaruh jenis pupuk kandang terhadap pertumbuhan dan hasil dua varietas okra.

\section{METODOLOGI PENELITIAN}

\section{Tempat dan Waktu Penelitian}

Penelitian ini dilaksanakan di Kebun Percobaan dan Laboratorium Fisiologi Tumbuhan Jurusan Agroteknologi Fakultas Pertanian Universitas Syiah Kuala, Darussalam, Banda Aceh pada ketinggian 0,80 mdpl, memiliki jenis tanah Alluvial dan dilaksanakan pada bulan Juni sampai dengan September 2019.

\section{Alat dan Bahan}


Alat

Timbangan analitik, ajir, cangkul, jangka sorong, plastik, hand sprayer, oven, amplop, gunting dan sarung tanagan.

\section{Bahan}

Benih Okra merah varietas Zahira IPB sebanyak 72 benih (15 g) dan Okra hijau varietas Naila IPB 72 benih $(15 \mathrm{~g})$, Decis $25 \mathrm{EC}$, tanah 1,08 ton, pupuk Urea sebanyak 108 g. SP 36 sebanyak 64,8 g, KCL sebanyak 81 g, pupuk kandang sapi 2,7 kg, pupuk kandang kambing 2,7 kg dan pupuk kandang ayam 2,7 kg.

\section{Rancangan Percobaan}

Penelitian ini menggunakan Rancangan Acak Kelompok (RAK) pola faktorial 2x4 terdiri dari 2 faktor yaitu: varietas okra (V) dan jenis pupuk kandang (K). Faktor pertama adalah varietas okra terdiri atas 2 taraf yaitu: Varietas Zahira IPB dan Naila IPB. Faktor kedua jenis pupuk kandang terdiri atas 4 taraf yaitu: Kontrol (tanah), Tanah + Pupuk kandang sapi, Tanah + Pupuk kandang kambing dan Tanah + Pupuk kandang ayam. Secara keseluruhan terdapat 8 kombinasi perlakuan. Masing-masing perlakuan diulang sebanyak 3 kali sehingga penelitian ini memiliki 24 satuan percobaan. Pada setiap satuan percobaan terdapat 3 tanaman sehingga terdapat 72 satuan percobaan. Data hasil penelitian di analisis dengan ANOVA. Apabila hasil uji $\mathrm{F}$ menjelaskan pengaruh nyata, maka analisis dilanjutkan dengan uji beda nyata jujur pada taraf 5\% (BNJ0,05)

\section{Pelaksanaan Penelitian}

Persiapan media tanam

Penelitian ini menggunakan media tanam berupa tanah Alluvial diambil di Ulee Kareng kemudian tanah dicampur pupuk kandang masing-masing perlakuan. Pupuk kandang sapi, kambing dan ayam yang diaplikasikan dengan dosis masing-masing 20 ton $\mathrm{ha}^{-1}$ (150 g.polibag $\left.{ }^{-1}\right)$. Pupuk kandang yang diberikan sudah terdekomposisi dengan sempurna. Kemudian tanah yang telah dimasukkan dalam polibag berukuran $50 \mathrm{~cm}$ x 50 $\mathrm{cm}$ (isi $15 \mathrm{~kg}$ ) dicampur dengan pupuk kandang dan diaduk hingga tercampur sempurna dengan tanah. Penanaman dilakukan 13 hari setelah tanah dicampur dengan pupuk kandang. Dipasang label pada polibag agar setiap perlakuan tidak ada yang tertukar.

\section{Penanaman}

Penanaman dilakukan secara langsung tanpa persemaian karena benih okra termasuk benih yang cukup besar bila ditanam di lapangan. Kedalaman lubang tanam untuk benih okra sekitar $5 \mathrm{~cm}$ dan masing-masing lubang tanaman dimasukkan 2 benih. Penanaman pada setiap polibag sesuai dengan varietas yang dicobakan. Setelah tanaman berumur 2 minggu di tinggalkan 1 tanaman untuk dipelihara dan disulam pada tanaman yang tidak tumbuh.

\section{Pemeliharaan}

Untuk mendapatkan hasil yang maksimal diperlukan pemeliharaan. Beberapa kegiatan pemeliharaan antara lain:

\section{Penyiraman}

Penyiraman okra dilakukan setiap hari pagi dan sore. Apabila hujan tidak perlu dilakukan penyiraman karena tanah tersebut sudah cukup basah.

\section{Penyiangan dan penggemburan tanah}


Penyiangan dilakukan setiap seminggu sekali agar tidak terjadi persaingan penyerapan unsur hara yang ada pada tanaman utama. Penggemburan dilakukan setiap 7 hari sekali agar tanah dapat menjadi lebih gembur dan perakaran tanaman dapat tumbuh dengan baik.

\section{Pemupukan}

Pada penelitian ini selain menggunakan pupuk kandang (perlakuan) juga ada digunakan pupuk dasar Urea dengan dosis $200 \mathrm{~kg} \mathrm{ha}^{-1}$ (1,5 g.polibag $\left.{ }^{-1}\right)$, pupuk SP 36 dengan dosis $120 \mathrm{~kg} \mathrm{ha}^{-1}\left(0,9\right.$ g.polibag $\left.{ }^{-1}\right)$ dan $\mathrm{KCL}$ dengan dosis $150 \mathrm{~kg} \mathrm{ha}^{-1}(1,125$ g.polibag $\left.{ }^{-1}\right)$. SP36, KCL, dan $1 / 2$ dosis Urea diberikan pada saat tanam, kemudian pada saat okra berumur 30 HST diberikan lagi $1 \frac{2}{2}$ dosis pupuk Urea.

\section{Pengendalian hama dan penyakit.}

Pada penelitian ini hama yang menyerang tanaman okra adalah kutu daun dan kutu putih, kepik hijau dan belalang. Kutu daun menyerang tanaman okra pada umur 24 HST pengendalian yang dilakukan menyemprotkan insektisida Decis 25 EC dengan konsentrasi $2 \mathrm{ml} /$ liter air. Kutu daun adalah serangga yang memiliki tubuh lunak. Umumnya berada dibawah daun atau batang tanaman. Kutu daun dapat menyebabkan daun tanaman mengerut dan mengerdil (Erminawati, 2018). Untuk kutu putih, kepik hijau dan belalang tidak dilakukan pengendalian karena jumlah hamanya tidak banyak.

\section{Pemanenan}

Okra dipanen pada umur 56 HST. Waktu pemanenan sangat memiliki pengaruh untuk kualitas buah yang dihasilkan karena apabila dibiarkan terlalu lama maka polongnya akan keras dan berserat. Panen dilakukan pada sore hari dengan interval waktu 2 hari sekali dan total pemanenan yang dilakukan sebanyak 12 kali panen. Buah okra yang dipanen merupakan buah muda berukuran $10-15 \mathrm{~cm}$ dan berdiameter 1,3-1,7 cm. Buah okra yang memiliki panjang sekitar $15 \mathrm{~cm}$ sudah tua tidak cukup baik untuk dipanen ataupun di makan untuk sayur. Karean rasa tidak enak dan keras. Ciri buah okra layak untuk di makan yaitu berwarna hijau muda pada okra hijau dan merah gelap pada okra merah dengan tekstur buah lembek. Jika buah okra dipanen lebih 7 hari, akan mengakibatkan permukaan buah keras, buah berwarna hijau tua pekat pada okra hijau dan buah lebih banyak memiliki lendir (Akhir et al., 2017).

\section{Parameter Pengamatan \\ Tinggi Tanaman (cm)}

Pengukuran tinggi tanaman okra dilakukan dari pangkal batang yang sudah diberi tanda sampai titik tumbuh tertinggi. Pengukuran tinggi tanaman dilakukan pada saat tanaman berumur 15, 30, 45, dan 60 HST.

\section{Diameter Pangkal Batang (mm)}

Diameter pangkal batang diukur dengan menggunakan jangka sorong, pengukuran dilakukan pada saat tanaman berumur 15, 30, 45, dan 60 HST.

\section{Berat Berangkasan Basah (g)}

Pengamatan berat berangkasan basah dilakukan setelah panen ke 12. Tanaman okra berbuah pada umur 56 HST hingga panen terakhir umur 98 HST. Perhitungan berat berangkasan basah dilakukan dengan cara mencabut tanaman okra selanjutnya dibersihkan tanah yang melekat pada akar kemudian ditimbang dengan timbangan analitik.

\section{Berat Berangkasan Kering (g)}


Pengamatan berat berangkasan kering dilakukan setelah menimbang berat berangkasan basah. Pengukuran dilakukan dengan cara memasukkan tanaman kedalam amplop yang telah diberikan label kemudian dimasukkan kedalam oven yang bersuhu $60^{\circ} \mathrm{C}$ selama 2x24 jam atau sampai berat konstan, setelah selesai selanjutnya ditimbang kembali dengan timbangan analitik.

\section{Jumlah Buah Pertanaman (buah)}

Jumlah buah pertanaman dihitung dengan cara menjumlahkan buah pada setiap kali panen yaitu dari panen $1-12$ dengan interval 2 hari sekali.

\section{Panjang Buah (cm)}

Pengukuran panjang buah dilakukan dengan mengukur dari pangkal buah hingga ujung buah. Menggunakan alat ukur berupa meteran. Setelah semuanya diukur maka dihitung rata-rata panjang buah, yaitu membagi total panjang buah dengan jumlah buah.

\section{Berat Buah Pertanaman (g)}

Pengamatan berat buah pertanaman dilakukan dengan menggunakan timbangan analitik. Berat buah dihitung dengan cara menjumlahkan berat buah pada setiap kali panen yaitu dari panen 1 - 12 dengan interval 2 hari sekali.

\section{Indeks Panen (g)}

Pengukuran indeks panen merupakan pengukuran yang paling terakhir dilakukan pada penelitian ini yaitu dengan membagi total berat buah pertanaman dengan berat berangkasan kering pertanaman.

\section{HASIL DAN PEMBAHASAN}

\section{Hasil Penelitian}

Pengaruh Jenis Pupuk Kandang terhadap Pertumbuhan dan Hasil Tanaman Okra

Hasil Uji F (lampiran 1 dan 3) menunjukkan bahwa jenis pupuk kandang berpengaruh nyata terhadap tinggi tanaman okra pada umur 45 HST dan berpengaruh sangat nyata terhadap tinggi tanaman umur 60 HST dan tidak berpengaruh nyata terhadap tinggi tanaman umur 15 dan 30 HST sedangkan perlakuan varietas berpengaruh nyata terhadap tinggi tanaman okra umur 15 dan 30 HST dan tidak berpengruh nyata terhadap tinggi tanaman umur 45 dan 60 HST Rata-rata tinggi tanaman okra pada umur 15, 30, 45 dan 60 HST setelah di uji dengan BNJ dapat dilihat pada Tabel 1.

Tabel 1 menunjukkan bahwa tinggi tanaman umur 45 HST tertinggi terdapat pada perlakuan pupuk kandang kambing yang berbeda nyata dengan kontrol, pupuk kandang sapi, dan pupuk kandang ayam. Tinggi tanaman umur 60 HST lebih tinggi terdapat pada perlakuan pupuk kandang kambing yang tidak berbeda nyata dengan perlakuan pupuk kandang ayam, akan tetapi berbeda nyata dengan kontrol dan pupuk kandang sapi.

Hasil penelitian menunjukkan bahwa pertumbuhan okra yang lebih baik terdapat pada perlakuan jenis pupuk kandang kambing. Pupuk kandang kambing masuk dalam golongan pupuk panas sedangkan pupuk kandang sapi dan ayam termasuk dalam golongan pupuk kandang dingin. Pupuk dingin merupakan pupuk yang terbentuk karena proses penguraian oleh mikroorganisme berlangsung secara perlahan-lahan sehingga tidak membentuk panas. Namun pupuk dingin lambat dalam proses perombakannya sehingga lambat pula tersedia bagi tanaman. 
Tabel 1. Rata-rata pertumbuhan dan hasil tanaman okra akibat perlakuan jenis pupuk kandang.

\begin{tabular}{|c|c|c|c|c|c|}
\hline \multirow[b]{2}{*}{ Parameter yang diamati } & \multicolumn{4}{|c|}{ Jenis Pupuk Kandang } & \multirow[b]{2}{*}{$\begin{array}{l}\mathrm{BNJ} \\
0,05\end{array}$} \\
\hline & Kontrol & $\begin{array}{c}\text { Pupuk } \\
\text { Kandang } \\
\text { Sapi }\end{array}$ & $\begin{array}{c}\text { Pupuk } \\
\text { Kandang } \\
\text { Kambing }\end{array}$ & $\begin{array}{c}\text { Pupuk } \\
\text { Kandang } \\
\text { Ayam }\end{array}$ & \\
\hline Tinggi tanaman 15 HST $(\mathrm{cm})$ & 6,50 & 7,67 & 7,94 & 6,44 & - \\
\hline Tinggi tanaman 30 HST $(\mathrm{cm})$ & 9,94 & 10,89 & 11,83 & 10,50 & - \\
\hline Tinggi tanaman 45 HST $(\mathrm{cm})$ & $29,39 \mathrm{~b}$ & $24,94 \mathrm{a}$ & $31,33 \mathrm{c}$ & $28,94 \mathrm{~b}$ & 3,82 \\
\hline Tinggi tanaman 60 HST $(\mathrm{cm})$ & $36,89 \mathrm{~b}$ & $32,22 \mathrm{a}$ & $41,78 \mathrm{c}$ & $40,00 \mathrm{c}$ & 4,66 \\
\hline $\begin{array}{c}\text { Diameter pangkal batang } 15 \\
\text { HST }(\mathrm{mm})\end{array}$ & 2,64 & 2,55 & 2,41 & 2,86 & \\
\hline $\begin{array}{c}\text { Diameter pangkal batang } 30 \\
\text { HST }(\mathrm{mm})\end{array}$ & 4,55 & 3,96 & 4,49 & 4,50 & - \\
\hline $\begin{array}{c}\text { Diameter pangkal batang } 45 \\
\text { HST }(\mathrm{mm})\end{array}$ & 9,95 & 9,00 & 10,60 & 10,70 & \\
\hline $\begin{array}{c}\text { Diameter pangkal batang } 60 \\
\text { HST (mm) }\end{array}$ & 14,30 & 13,73 & 16,10 & 15,74 & - \\
\hline Berat berangkasan basah (g) & 227,62 & 266,59 & 297,77 & 215,38 & - \\
\hline Berat berangkasan kering (g) & 85,26 & 99,80 & 114,24 & 90,93 & - \\
\hline $\begin{array}{l}\text { Jumlah buah pertananam } \\
\text { (buah) }\end{array}$ & 13,06 & 13,33 & 14,11 & 13,33 & - \\
\hline Panjang buah (cm) & 12,08 & 12,02 & 12,49 & 12,06 & - \\
\hline Berat buah pertanaman (g) & 280,03 & 281,54 & 295,65 & 288,31 & - \\
\hline Indeks panen $(\mathrm{g})$ & 3,44 & 2,94 & 2,64 & 3,25 & - \\
\hline
\end{tabular}

Keterangan : Angka yang diikuti oleh huruf yang sama pada baris yang sama berbeda tidak nyata pada uji beda nyata jujur taraf $5 \%\left(\mathrm{BNJ}_{0,05}\right)$

Pupuk kandang sapi dan ayam akan lebih cocok digunakan untuk tanah yang ringan bakteri dan jasad reniknya yang akan membuat pupuk kandang sapi dan ayam dapat berperan lebih intensif untik dapat mempercepat proses tersedianya hara agar tanaman dapat lebih cepat memanfaatkan hara tersebut untuk membantu pertumbuhan menjadi lebih baik. Salah satu pupuk yang masuk dalam golongkan pupuk kandang panas adalah pupuk kandang kambing karena pupuk kandang kambing terbentuk akibat dari penguraian oleh mikroorganisme yang berlangsung dengan cepat sehingga terbentuknya panas (Arifah, 2013). Penggunaan pupuk kandang sapi dan ayam lebih baik digunakan setelah empat minggu percampuran pupuk dengan tanah (Khomsug et al., 2010). Pada penelitian ini penanaman di lakukan pada saat seminggu setelah tanah di campur dengan pupuk kandang. karena itulah pupuk kandang kambing memiliki hasil yang lebih tinggi karena proses penguraiannya lebih cepat sehingga unsur hara lebih cepat diserap oleh tanaman. Selain itu kotoran kambing memiliki $\mathrm{pH}$ lebih seimbang dan lebih sedikit garam. Ini juga jauh lebih kering dari pada kotoran ayam. Kotoran kambing memungkinkan menyerap lebih banyak udara di dalam tanah, karena sifat kering akan mempercepat penguraian dan dapat meningkatkan kualitas tanah sehingga memungkinkan oksigen lebih banyak dan 
penggunaan air lebih efisien mengakibatkan tanaman lebih mudah menyerap unsur hara (Marschner, 2012).

Pupuk kandang berpengaruh nyata pada tinggi tanaman umur 45 dan 60 HST, hal ini dikarenakan pada awal pertumbuhan akar belum berkembang secara optimal sehingga menyebabkan tanaman belum bisa menyerap semua unsur hara yang ada didalam tanah. Ketika tanaman okra berumur 45 dan 60 HST akar tanaman sudah berkembang dengan baik dan tumbuh menyebar sehingga membuat daerah penyerapan menjadi luas, memungkinkan untuk menjangkau air dan unsur hara hingga ke tempat yang jauh. Selain akar, daun juga memiliki peran penting dalam pertumbuhan tanaman okra. Tempat mengolah zat makanan yang ada pada tanaman adalah daun. Proses pengolahan makan yang ada pada tanaman disebut fotosintesis. Proses terjadinya fotosintesis di karenakan cahaya matahari diserap oleh klorofil daun dan kemudian cahaya tersebut diubah menjadi energi kimia yang kemudian disimpan dalam bentuk karbohidrat atau senyawa lainnya (Rochmah, 2009).

Pada parameter tinggi tanaman umur 15 dan 30 HST, diameter pangkal batang 15, 30, 45, dan 60 HST, berat berangkasan basah, berat berangkasan kering, jumlah buah pertanaman, panjang buah berat buah pertanaman dan indeks panen, pupuk kandang tidak menunjukkan pengaruh yang nyata hal ini diduga karena pupuk kandang belum dapat memenuhi sifat fisik, kimia dan biologi tanah. Keseimbangan yang ada pada hara dan tanah sangat mempengaruhi kelarutan unsur hara. Tanah yang dikatakan subur adalah tanah yang memiliki keseimbangan hara, bukan kerena suatu unsur tersebut lebih banyak. Penyerapan yang baik dapat mempengaruhi keseimbangan hara yang ada dalam tanah yang dapat membuat tanaman tersebut memiliki produksi yang lebih tinggi (Pincus et al., 2016).

\section{Pengaruh Varietas terhadap Pertumbuhan dan Hasil Tanaman Okra}

Hasil Uji F menunjukkan bahwa perlakuan varietas berpengaruh nyata terhadap tinggi tanaman okra umur 15 dan 30 HST dan tidak berpengruh nyata terhadap tinggi tanaman umur 45 dan 60 HST, diameter pangkal batang umur 15, 30, 45, dan 60 HST, berat berangkasan basah, berat berangkasan kering, jumlah buah pertanaman, panjang buah, berat buah pertanaman dan indeks panen. Rata-rata pertumbuhan dan hasil tanaman okra akibat perlakuan varietas dapat dilihat pada Tabel 2.

Tabel 2 menunjukkan bahwa tinggi tanaman umur 15 HST dan 30 HST nilai tertinggi terdapat pada perlakuan varietas Naila IPB yang berbeda nyata dengan varietas Zahira IPB. Berdasarkan hasil penelitian yang telah dilakukan menunjukkan bahwa tinggi tanaman okra umur 15 dan 30 HST yang lebih baik terdapat pada varietas Naila IPB, hal ini diduga tinggi tanaman sangat dipengaruhi oleh faktor genetik. Perbedaan pertumbuhan antar varietas mengakibatkan adanya perbedaan kecepatan pembelahan, perbanyakan dan pembesaran sel. Varietas berpengaruh terhadap parameter tinggi tanaman yang di akibatkan oleh perbedaan faktor genetik pada masing-masing varietas dan kemampuan adaptasinya dengan lingkungan (Gardner et al., 1991). Setiap varietas memiliki masingmasing ciri dan sifat yang berbeda. Menurut literatur Sitompul dan Guritno (1995) perbedaan yang ada pada susunan genetik adalah salah satu penyebab keaneka ragaman dari panampilan yang ada pada tanaman. Penampilan pada setiap varietas tanaman yang berbeda di karenakan adanya perbedaan kecepatan pembelahan, perbanyakan da pembesaran sel. Sifat genetik yang tampak pada setiap tanaman merupakan sifat tanaman yang mencangkup bentuk dan fungsi tanaman yang akan membuat berbagai macam keanekaragaman. 
Tabel 2. Rata-rata pertumbuhan dan hasil tanaman akibat perlakuan dua varietas okra.

\begin{tabular}{cccc}
\hline & \multicolumn{2}{c}{ Varietas okra } & \\
\cline { 2 - 3 } Parameter yang diamati & Varietas Zahira & Varietas Naila & BNJ $_{0,05}$ \\
& IPB & IPB & \\
\hline Tinggi tanaman 15 HST (cm) & $6,33 \mathrm{a}$ & $7,94 \mathrm{~b}$ & 1,76 \\
Tinggi tanaman 30 HST (cm) & $10,17 \mathrm{a}$ & $11,42 \mathrm{~b}$ & 1,69 \\
Tinggi tanaman 45 HST (cm) & 28,42 & 28,89 & - \\
Tinggi tanaman 60 HST (cm) & 38,97 & 36,47 & - \\
Diameter pangkal batang 15 HST (mm) & 2,50 & 2,73 & - \\
Diameter pangkal batang 30 HST (mm) & 4,42 & 4,33 & - \\
Diameter pangkal batang 45 HST (mm) & 10,04 & 10,08 & - \\
Diameter pangkal batang 60 HST (mm) & 15,33 & 14,60 & - \\
Berat berangkasan basah (g) & 246,86 & 256,82 & - \\
Berat berangkasan kering (g) & 101,32 & 93,80 & - \\
Jumlah buah pertananam (buah) & 13,17 & 13,75 & - \\
Panjang buah (cm) & 12,20 & 12,12 & - \\
Berat buah pertanaman (g) & 283,72 & 289,04 & - \\
Indeks panen (g) & 2,87 & 3,26 & - \\
\hline
\end{tabular}

Keterangan : Angka yang diikuti oleh huruf yang sama pada baris yang sama berbeda tidak nyata pada uji beda nyata jujur taraf $5 \%\left(\mathrm{BNJ}_{0,05}\right)$

Okra varietas Naila IPB memiliki jumlah daun yang cenderung lebih banyak dibandingkan okra varietas Zahira IPB. Pada okra varietas Naila IPB setiap ketiak daun ditumbuhi cabang yang akan menghasilkan buah. Karena itulah jumlah buah yang ada pada okra varietas Naila IPB cendrung lebih banyak dibandingkan okra varietas Zahira IPB. Menurut Manik et al. (2019) selain cabang itu hal lain yang menyebabkan jumlah buah pada okra varietas Naila IPB lebih banyak di bandingkan okra varietas Zahira IPB

Ini di karenakan okra hijau memiliki kemampuan untuk menyerap unsur hara $\mathrm{N}$ dan $\mathrm{K}$ yang lebih tinggi dibandingkan dengan tanaman okra varietas Zahira IPB, karena pada daun memiliki kadar $\mathrm{N}$ dan $\mathrm{K}$ lebih tinggi pada okra hijau jauh lebih tinggi di bandingkan okra varietas Zahira IPB. Unsur kalim memilki salah satu petan untuk memacu translokasi asimilat dari sumber ke bagian organ yang ada di penyimpanan. Hal ini yang membuat tanaman okra hijau mampu memiliki jumlah daun yang lebih banyak dan dapat meningkatka produksi buah yang lebih banyak dan juga buah pertanaman jadi lebih tinggi. Pada setiap ketiak daun yang ada pada buah okra akan menghasilkan buah dan apabila sudah berbuah mka di ketiak daun selanjutnya tidak akan berbuah lagi.

Okra merah varietas Zahira IPB memiliki tinggi tanaman yang lebih rendah di bandingkan dengan okra hijau varietas Naila IPB. Jika tinggi tanaman terus bertambah maka pembentukan buku tanaman akan semakin meningkat sriap buku yang baru akan menjadi tempat yang potensial untuk pembentukan tunas tanaman kemudian akan bercabang dan menghasilkan buah. Hal ini yang membuat tanaman okra varietas Naila IPB memiliki jumlah buah pertanaman yang lebih tinggi. Tanamn yang baik adalah tanaman yang memiliki fotosintesis yang baik yang ditandai dengan pertumbuhan cabang, batang, daun dan akar. Dengan demikian fotosintat yang dihasilkan lebih banyak dan kemudian 
fotosintat pada tanaman tersebut di gunakan untuk pertumbuhan bunga dan buah sehingga menghasilkan produksi yang lebih tinggi (Barus, 2018).

\section{Pengaruh Interaksi antara Perlakuan Dua Varietas Okra dengan berbagai jenis Pupuk Kandang}

Tabel 3 menunjukkan bahwa tinggi tanaman okra pada perlakuan kontrol varietas Zahira IPB berbeda nyata dengan varietas Naila IPB. Perlakuan pupuk kandang sapi varietas Zahira IPB tidak berbeda nyata dengan varietas Naila IPB. Perlakuan pupuk kandang kambing varietas Zahira IPB tidak berbeda nyata dengan varietas Naila IPB. Begitu juga dengan jenis pupuk kandang ayam.

Tabel 3. Interaksi antar perlakuan varietas dengan jenis pupuk kandang terhadap tinggi tanaman pada umur 60 HST.

\begin{tabular}{cccccc}
\hline & \multicolumn{4}{c}{ Jenis Pupuk Kandang } & \\
\cline { 2 - 5 } Varietas okra & Kontrol & $\begin{array}{c}\text { Pupuk } \\
\text { Kandang } \\
\text { Sapi }\end{array}$ & $\begin{array}{c}\text { Pupuk } \\
\text { Kandang } \\
\text { Kambing }\end{array}$ & $\begin{array}{c}\text { Pupuk } \\
\text { Kandang } \\
\text { Ayam }\end{array}$ & BNJ 0,05 \\
Zahira IPB & $41,9 \mathrm{~cd}$ & $35,6 \mathrm{abc}$ & $40 \mathrm{~cd}$ & $38,4 \mathrm{bcd}$ & \multirow{2}{*}{6,93} \\
Naila IPB & $31,9 \mathrm{ab}$ & $28,9 \mathrm{a}$ & $43,6 \mathrm{~d}$ & $41,6 \mathrm{~cd}$ & \\
\hline
\end{tabular}

Keterangan : Angka yang diikuti oleh huruf yang sama berbeda tidak nyata pada uji beda nyata jujur taraf $5 \%\left(\mathrm{BNJ}_{0,05}\right)$

Berdasarkan hasil penelitian terdapat interaksi antara jenis pupuk kandang dengan varietas okra terhadap tinggi tanaman umur $60 \mathrm{HST}$. Nilai rata-rata yang paling tinggi terdapat pada perlakuan varietas Naila IPB dan pupuk kandang kambing hal ini diduga pupuk kandang belum bisa di serap dengan sempurna hingga pada tinggi tanaman umur 15, 30 dan 45 HST belum terdapat interaksi. Tanaman yang masih muda memiliki akar yang masih sedikit dan lemah, belum sempurna sistem perakarannya, sehingga belum mampu menyerap unsur hara dengan baik.

Tinggi tanaman merupakan bentuk pengekpresian sifat dari suatu varietas tanaman terkait dengan sifat yang dimiliki dan dipengaruhi oleh lingkungan dimana varietas tersebut dibudidayakan. Munculnya karakter tanaman adalah akibat adanya interaksi genotip dan lingkungan, jika lingkungan sesuai dengan yang diharapkan, maka hasil akan maksimal namun sebaliknya jika lingkungan kurang mendukung, maka akan mengakibatkan hasilnya tidak berbeda dengan varietas yang lain. Setiap genotip dimiliki oleh varietas yang berbeda yang menyebabkan tampilan dari fenotipe pada tanaman juga berbeda tergantung lingkungan.

Marliah et al., (2012) menyatakan masing-masing varietas memiliki tingkat ketahanan yang berbeda, beberapa tanaman dapat melakukan adpatasi dengan cepat namun sebaliknya ada beberapa tanaman yang membutuhkan waktu lama untuk dapat beradaptasi dengan lingkungan. Hal ini disebabkan masing-masing varietas memiliki potensi genetik yang berbeda dalam merespon lingkungan tempat tumbuhnya. Lingkungan juga dapat menyebabkan munculnya keragaman sifat dari suatu tanaman. Varietas dapat menunjukkan hasil yang tinggi, jika ditanam pada lingkungan tumbuh yang sesuai, namun jika keadaan lingkungan yang tidak sesuai maka varietas itu dapat menunjukkan potensi hasil yang 
rendah. Masing-masing varietas memiliki perbedaan dalam kemampuannya untuk mempertahankan hidup dan pertumbuhan individu tanaman yang sesuai dengan iklim tempat tumbuhnya. Faktor genetik tanaman dan cara adaptasinya terhadap lingkungan dapat mempengaruhi pertumbuhan tanaman yang berbeda-beda.

Faktor genetik dan lingkunagn berpengaruh terhadap varietas karena akan mempengaruhi pertumbuhan dan hasil yang beragam. Pengaruh genetik berasal dari keturunan yang berasal dari setiap galur sedangkan pengaruh lingkungan adalah pengaruh yang di timbulkan oleh kondisi lingkungan dan habitat yang ada di alam. (Marliah et al., 2012).

Unsur hara merupakan salah satu faktor lingkungan yang mendukung pertumbuhan tanaman okra. Pupuk kandang kambing mengandung N, P, K dan C organik yang besar dibandingkan pupuk kandang yang lainnya. Unsur hara dibutuhkan oleh tanaman untuk merangsang pertumbuhan tanaman, pembentuk zat hijau yang berguna untuk fotosintesis, membantu pemasakan biji dan buah, memperkuat tubuh tanaman dan agar tahan dari penyakit dan kekeringan. Pupuk kandang kambing memiliki ketersediaan $\mathrm{N}$ dan P yang cukup untuk meningkatkan pertumbuhan organ-organ tanaman okra, salah satu fungsi $\mathrm{N}$ dan $\mathrm{P}$ adalah berguna untuk proses pembentukan daun (Maghfoer et al., 2013). $\mathrm{N}$ dan P sangat berguna untuk tanaman okra hijau varietas Naila IPB karena pada okra hijau memiliki daun yang banyak sehingga unsur hara $\mathrm{N}$ dan $\mathrm{P}$ sangat diperlukan untuk perkembangan (Livestock and Poultry Environmental Learning Community, 2019).

\section{KESIMPULAN}

Jenis pupuk kandang berpengaruh sangat nyata terhadap tinggi tanaman 60 HST dan berpengaruh nyata terhadap tinggi tanaman umur 45 HST. Pertumbuhan yang lebih baik dijumpai pada perlakuan pupuk kandang kambing. Varietas okra berpengaruh nyata terhadap tinggi tanaman umur 15 dan 30 HST. Pertumbuhan yang terbaik di jumpai pada perlakuan okra varietas Naila IPB. Terdapat interaksi yang nyata antara perlakuan dua varietas dengan jenis pupuk kandang terhadap tinggi tanaman umur 60 HST. Kombinasi perlakuan yang terbaik baik dijumpai pada pupuk kandang kambing dan okra hijau varietas Naila IPB.

\section{DAFTAR PUSTAKA}

Akhir, N., D. Hayati dan Ardi. 2017. Fenologi pembangunan, viabilitas dan vigor benih dua genotipe okra Abelmoschus esculentus L.(Moench) di Kota Padang. Laporan Hasil Penelitian Dana PNBP Fakultas Pertanian Tahun 2017. Fakultas Pertanian Universitas Andalas.

Arifah, S. M. 2013. Aplikasi macam dan dosis pupuk kandang pada tanaman kentang. Jurnal GAMMA. 8 (2) : $80-85$.

Badan Litbang Pertanian Kementrian Pertanian Republik Indonesia. 2019. Varietas Unggul. http://www.litbang.pertanian.go.id/varietas/?d=\&s=n. Diakses pada 28 Maret 2019.

Barus, R. A. A., C. Hanum dan R. Sipayung. 2018. Respons pertumbuhan dan produksi dua varietas okra (Abelmoschus esculentus L. Moench) terhadap pemberian berbagai jenis pupuk organik. Agroekoteknologi. 6 (40): 253 - 258.

Erminawati. 2018. Budi Daya Okra. Mitra Sarana Edukasi, Bandung. 
Gardner, F. P., R. B. Pearce and R. L. Mitchel. 1991. Physiology of Crop Plants. Universitas Indonesia Press, Jakarta.

Hariyadi, P. 2009. Mutu buah (dan sayuran). Foodreview Indonesia. 4:16-19.

Ibrahim, M.H., H.Z.E. Jaafar, E. Karimi, A. Ghasemzadeh. 2013. Impact of organic and inorganic fertilizers application on the phytochemical and antioxidant activity of kacip fatimah (Labisia pumila. Benth). Molecules. 18:10973-10988.

Khomsug, P., W. Thongjaroenbuangam, N. Pakdeenarong, M. Suttajit dan P. Chantiratikul. 2010. Antioxidative activities and phenolic content of extracts from okra (Abelmoschus esculentus L.). Res. J. Biol. Sci. 5: 310-313.

Kumar, D. S., D. E. Tony, A. P. Kumar, K. A. Kumar, D. B. S. Rao dan R. Nadendla. 2013. A review on: Abelmoschus esculentus (okra). Int. Res J Pharm. 3 (4): 129132.

Livestock and Poultry Environmental Learning Community. 2019. Environmental Benefits of Manure Application. https://lpelc.org/environmental-benefits-of-manureapplication/. Diakses pada 30 Okteber 2019.

Maghfoer. M. D., R. Soelistyono and N. Herlina. 2013. Response of eggplant (Solanum melongena L.) to combination of inorganic-organic $\mathrm{N}$ and EM4. Journal of Agricultural Sciences. 35 (2) : 126- 537

Maisa dan H. Yetti. 2018. Pemberian berbagai dosis pupuk kandang ayam terhadap pertumbuhan dan produksi tanaman bawang daun (Allium fistulosum L.). UNRI. 5 (1): $20-21$.

Manik, A. E. S., M. Melati, A. Kurniawati dan D. N. Faridah. 2019. Hasil dan kualitas okra merah (Abelmoschus esculentus L. Moench.) dan okra hijau dengan jenis pupuk yang berbeda. Jurnal Agronomi. 47(1):68-75.

Marliah, A., T. Hidayat dan N. Husna. 2012. Pengaruh varietas dan jarak tanam terhadap pertumbuhan kedelai (Glycine max (L.) Merrill). Jurnal Agrista. 16 (1): 24-27.

Marschner, P. 2012. Marschner's Mineral Nutrition of Higher Plants. Academic Press, San Diego, USA.

Muhammad, U. 2015. Cow dung, goat and poultry manure and their effects on the average yields and growth parameters of tomato crop. Biology. 5 (5): 7-10.

Pincus, L., A. Margenot, J. Six , K. Scow. 2016. On-farm trial assessing combined organic and mineral fertilizer amendments on vegetable yields in central Uganda. Agriculture, Ecosystems and Environment. 225(2016): 62-71.

Rochmah, H. F. 2009. Pengaruh pupuk organik dan anorganik terhadap pertumbuhan dan hasil padi sawah (Oryza sativa L.). Skripsi. Institut Pertanian Bogor. Bogor

Sitompul, S. M. dan Guritno. 1995. Analisis Pertumbuhan Tanaman. UGM Press, Yogyakarta.

Uwah, D. F. dan V. E. Eyo. 2014. Effects of number and rate of goat manure application on soil properties, growth and yield of sweet maize (Zea mays L. saccharata Strut). Sustainable Agriculture Research. 3 (4): 75-83.

Wasito, P. 2018. Tanaman Okra (Abelmoschus esculentus L.) Berkah Kesehatan dari Alam. Universitas Bandung Raya Press, Bandung.

Watson, R. R. dan V. R. Preedy. 2016. Fruits, Vegetables, and Herbs. Academic Press, London.

Wibowo, R.H., A.D. Susila dan J.G. Kartika. 2015. Peningkatan pertumbuhan dan hasil tanaman gedi [Abelmoschus manihot (L.) Medik.] melalui aplikasi pupuk organik dan pupuk anorganik. Bul. Agrohorti 3:193-202. 